\title{
Unconventional methods for displaying tectonic features of architectural systems of low-rise buildings
}

\author{
Alexander Pleshivtsev ${ }^{1, *}$ \\ ${ }^{1}$ State University of Land Management, 15, Kazakova St., 105064, Moscow, Russia
}

\begin{abstract}
The possibilities of unconventional technological methods for the formation of low-rise buildings need an adequate scientific and methodological substantiation. The features of the influence of technological component on the nature and methods of forming compositional solutions of low-rise buildings are established. The dependence of the functional quality of construction products (low-rise buildings) on the possibilities of adapting techniques of unconventional technological effectiveness to the practical implementation of compositional and structural solutions of effective architectural systems has been revealed. The structure of promising areas of technological transformation of forms (dynamic architecture) of low-rise buildings is developed. An example of the concept of technological transformation of a mobile architectural system of a low-rise residential building is considered. The main features of the influence of unconventional technological methods on compositional solutions and methods of forming architectural systems of low-rise buildings are determined.
\end{abstract}

\section{The characteristic of unconventional methods of technological effectiveness of the formation of architectural characters}

From the earliest historical periods, meeting the human need for ensuring life support processes in the most remote (geographically) territories available for organizing the construction of architectural objects is considered among the priority tasks of architectural science [1-4].

The format of low-rise construction can be recognized as the most common (of historic and geographic proportions) way of organizing a closed architectural space. The use of compositional solutions in the form of low-rise buildings (primarily residential and public buildings) determined the conditions and opportunities for various combinations of architectural systems, building materials, construction techniques, and means of artistic expression.

Practical examples of the implementation of low-rise construction objects characterize certain (traditional) types of constructive, technological and artistic techniques, which now

\footnotetext{
*Corresponding author: perspektiva-aa@mail.ru
} 
are a certain standard of compositional and construction solutions. One of the main features of modern architectural activity is the need to increasingly create architectural characters that have not been previously considered due to the fundamental (technological) impossibility of solving the proposed problems.

The modern level of technical (technological) perfection, combined with the sharply increased importance of intellectual capital, strongly implies the research and development of a solid and methodologically sound symbiosis of architectural knowledge (theoretical foundations and practical experience), building science and technological opportunities for implementation in architectural creativity [5-9].

The solution of problems associated with the development of technological techniques and methods of designing, manufacturing and erecting buildings is accompanied by the development of general theoretical knowledge of architectural science and building materials science as ways to improve the quality and scope of architectural systems and their tectonic display in the format of low-rise buildings.

The positive effect associated with the development of areas related to the development of effective, innovative techniques for the formation of architectural systems of low-rise buildings includes:

- $\quad$ reducing the time and complexity of the formation of building products (including architectural systems of low-rise buildings) of established functional quality;

- an increase in the innovative and investment attractiveness of the construction industry, indicators of the functional quality of construction products;

- qualitative and quantitative improvement of the overall culture of architectural and construction activities.

An analysis of the genesis of the methods and techniques for the formation of architectural systems of low-rise buildings indicates a certain tendency and priority commitment to the use of a widespread and accessible raw material base from natural building materials.

The use of traditional techniques of formation in combination with the use of canonical techniques of architectural creativity corresponded to the requirements and results of the relevant architectural and construction activities in the past. Promising techniques of unconventional technological effectiveness can significantly expand the possibilities of architectural creativity (while maintaining the canonical approach to architectural composition) to form a new level of quality for well-known types of construction products and fundamentally new and effective architectural systems of low-rise buildings $[10 ; 11$; $12 ; 13]$.

The presence of unconventional technological methods does not deny the possibility of designing and erecting traditional architectural systems (using traditional, mainly natural building materials), but it can significantly increase the stability of low-rise buildings in natural and climatic influences, the level of functional quality, comfort and safety of the internal space, to ensure possibilities of the modern information and communication environment.

At the same time, the rational use of unconventional technological methods makes it possible to (while ensuring the established level of functional quality of construction products):

- $\quad$ expand the range of possible compositional solutions;

- reduce the level of material costs (cost, duration and complexity) of construction and operating costs;

- minimize the amount of environmental impact;

- increase adaptability to conditions of harmonious interaction with the surrounding artificial and natural environment. 
The use of unconventional technological methods and techniques for the formation of architectural systems of low-rise buildings is a new, innovative, and also competitive (in relation to traditional types) way of organizing the architectural space.

\section{Technological transformation of forms (dynamic architecture) of architectural systems of low-rise buildings}

One of the characteristic features of the application of traditional techniques and solutions within the architectural activity is the formation of a static property that reflects the strength and stability of architectural systems of low-rise buildings.

The static property of a low-rise building is formed by both traditional and unconventional compositional solutions, methods of technological effectiveness, and the properties of building materials and reflects the classical approach to displaying tectonic features (primarily stability) of an architectural system $[14 ; 15 ; 16 ; 17]$.

Figure 1 presents examples (results) of architectural activity in the area of formation of low-rise buildings using traditional and unconventional technological methods.

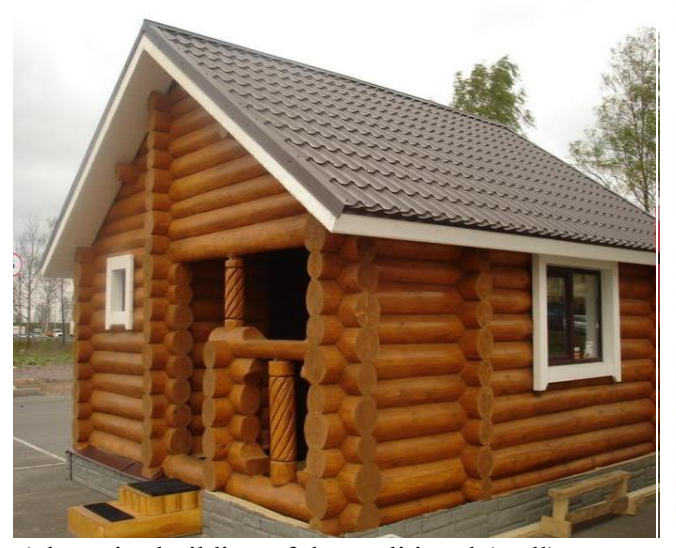

a) low-rise building of the traditional (wall) architectural system from natural materials

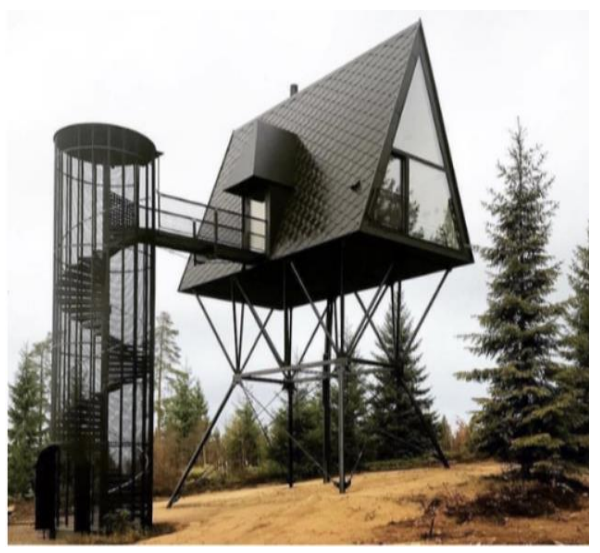

b) low-rise building of the unconventional architectural system from artificial materials

Fig. 1. Methods of forming a low-rise building using traditional and unconventional types of architectural systems and materials.

The concept of a "dynamic" architectural object (including low-rise buildings and structures) is presented in the form of an innovative area of architectural activity, focused on the technological transformation of traditional systems through the use of $[18 ; 19 ; 20$; 21]:

- individual, aesthetic and functional forms as part of a holistic compositional solution (and priority consideration of the property of technological effectiveness);

- ergonomic and emotional display of tectonic features of moving architectural systems;

- rational ways of organizing interaction (adaptation) of the closed internal space of the architectural character with the open space of the environment.

Figure 2 presents a structural diagram of the main areas and varieties of architectural activity in relation to the possibilities of technological transformation of architectural systems (objects of dynamic architecture). 


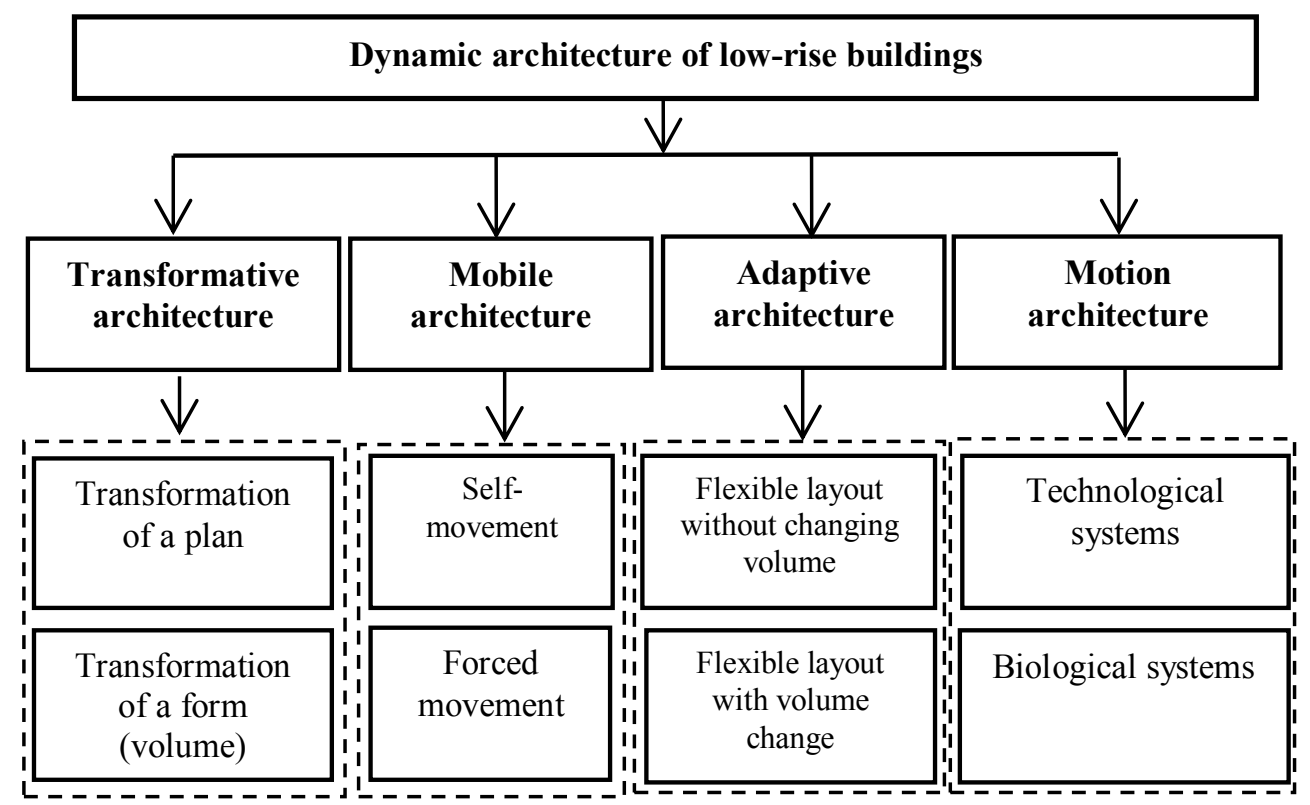

Fig. 2. The structure of the areas of formation of dynamic architecture objects.

The basis of the architectural concept of a "dynamic" architectural system of a low-rise building is the use of a new formative potential based on the principles of dynamic adaptation of an architectural object to the conditions of interaction with the environment through integrated innovative technologies $[22 ; 23 ; 24 ; 25]$.

In the broadest sense, the concept of "dynamic architecture" includes a number of areas related to the spatial change (movement, motion) of architectural objects as a whole or their individual structural elements (walls, columns, ceilings).

The main direction of the development of mobile properties (features) of an architectural system is to provide additional properties and possibilities for transforming the spatial position of structural elements (module) of a mobile architectural system.

Figure 3 shows the main acceptances of one of the areas of the prospective development of the concept of technological transformation of the mobile architectural system of a low-rise building [26].

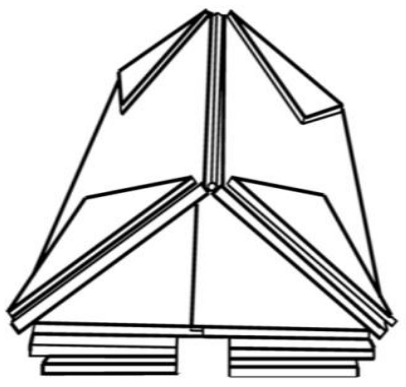

a) formation of a structural component at the factory

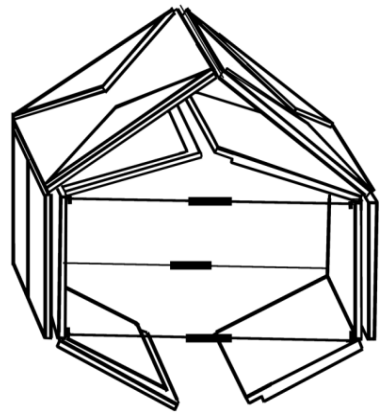

b) formation of a building system in the area of location

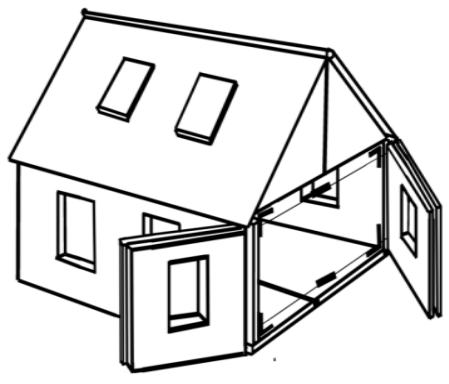

c) formation of the architectural system for established operating conditions

Fig. 3. Stages of technological transformation of the form of a mobile architectural system of a lowrise building. 
A dialogue with architectural objects formed on the properties and features of unconventional technological effectiveness allows the transition to new opportunities for displaying innovative architectural systems of low-rise buildings.

\section{Results}

The study revealed the possibilities of using innovative technological methods for the formation of a new functional quality of architectural systems using the technological transformation of the form of a low-rise residential building as an example.

The analysis of the conceptual areas of the development of applied knowledge of architectural science (dynamic architecture) related to the study of the possibilities of practical implementation of new (unconventional) technological capabilities is carried out.

\section{Discussion}

Addressing the issues of theory and practice of using unconventional (innovative) technological methods for technological transformation of the forms of architectural systems of low-rise buildings in the most promising (innovative) areas of architectural activity is becoming sustainable.

The use of various aspects of unconventional technological effectiveness is still of a great interest, which is accompanied by the publication of a fairly large number of theoretical works published in periodicals and on electronic information portals.

To a large extent, the techniques of unconventional technological effectiveness are focused on the adaptation and implementation of innovative methods and developments from related fields of knowledge: building materials science, engineering, technology, organization and management of construction production.

\section{Conclusion}

The ability and tendency of architectural systems to constructive, functional and tectonic transformations seems to be a promising area of application and development of more technological methods of forming the space of architectural objects (low-rise construction objects) of various functional and technological purposes.

\section{References}

1. M.V. Shubenkov, The structure of the architectural space: a thesis for the Doctor of Architecture degree (Moscow, 2006)

2. G. Bachelard, The Poetics of Space (Penguin Classics, London, 2014)

3. K.A. Soloviev, D.S. Stepanova, History of architecture and construction equipment ("Lan" Publishing House, St. Petersburg, 2016)

4. M.A. Cohen, M. Delbeke, Proportional Systems in the History of Architecture: A Critical Reconsideration (Leiden University Press. Critical edition, London, 2018)

5. S.A. Mouzon, D.L. Mouzon, Architectural elements. Traditional construction details (McGraw-Hill Book Company, New York, 2001)

6. T. Hyde, Journal of Architectural Education 69(2), 1-3 (2015)

7. C. Kulper, Architectural Theory Review 6(3), 312-314 (2011) 
8. A. Mottaeva, , E3S Web of Conferences, 110, 02166, (2019) doi.org/10.1051/e3sconf /201911002166

9. M. Riley, A. Cotgrave, Construction Technology 1: House Construction (Red Globe Press, London, 2018)

10. C.D. Elliott, Technics and Architecture: The Development of Materials and Systems for Building (The MIT Press, New-York, 1992)

11. J. Ambrose, Building Structures (Wiley, NewYork, 2008)

12. E.V. Sysoeva, S.I. Trushin, E.E. Kuznetsova, V.P. Konovalov, Architectural structures and design theory: low-rise residential buildings (Infra-M, Moscow, 2018)

13. M. Atkinson, Structural Foundations Manual for Low-Rise Buildings (CRC Press, New-York, 2014)

14. N. Lahiji, An Architecture Manifesto (2019) DOI: 10.4324/9781138606678-6

15. Y. Hurol, The Tectonics of Structural Systems (Routledge. Tayler \& Francis Group, London, 2015)

16. N.A. Saprykina, Fundamentals of dynamic forming in architecture (Architecture-S, Moscow, 2005)

17. Ch. Schwartz, Introducing Architectural Tectonics: Exploring the Intersection of Design and Construction (Routledge, London, 2016)

18. M. Fazio, M. Moffett, L. Wodehouse, A World History of Architecture (McGraw-Hill Education, New York, 2008)

19. R. Arnheim, The Dynamics of Architectural Form (University of California Press, Oakland, 2009)

20. P. Blundell Jones, M. Meagher, Architecture and Movement: the Dynamic Experience of Buildings and Landscapes (Routledge, New York, 2014)

21. R. Fortmeyer, Ch. Linn, Kinetic Architecture: Designs for Active Envelopes (Images Publishing Dist Ac., New York, 2014)

22. Ch. Abel, Architecture, Technology and Process (Architectural Press, London, 2004)

23. R. Klanten, The Tale of Tomorrow. Utopian Architecture in the Modernist Realm. Die Gestalten (Verlag, Berlin, 2016)

24. A. Aksamija, Integrating Innovation in Architecture: Design, Methods and Technology for Progressive Practice and Research (Academy Press, London, 2017)

25. A. Watts, Modern Construction Case Studies: Emerging Innovation in Building Techniques (Birkhauser Architecture, Berlin, 2019)

26. I.Kh. Nanazashvili, A.A. Pleshivtsev, V.I. Nanazashvili, RF patent No. 2445423, 20.03.2012. Prefabricated self-assembly low-rise foldable building with an attic, Bulletin No. 33 (2012) 